\title{
Docência no Ensino Médico: por que É Tão Difícil Mudar?
}

\author{
Medical Teaching: why Is it so difficult to \\ change?
}

Nilce Maria da Silva Campos Costa ${ }^{1}$

PALAVRAS-CHAVE:

- Educação em Saúde;

- Educação Médica;

- Docentes de Medicina.

\section{KEY-WORDS:}

- Health Education;

- Education Medical;

- Faculty, Medical.

Recebido em: 29/07/2005

Reencaminhado em: 24/10/2006

Aprovado em: 25/01/2007

\section{ABSTRACT}

Although there is a recognized need for changes in medical teaching, professors have shown resistance to modifications. This review identifies the factors that limit changes in the teaching practice in medicine. Among the identified factors we emphasize the depreciation of the teaching activities and supremacy of research, the lack of professional identity, the deficient pedagogic education of the medical teacher, the resistance of the teaching body to changes and the individualism of university professors. It is necessary to stimulate permanent professional development of medicine professors as an instrument of re-creation and transformation of the teaching practice. 


\section{INTRODUÇÃO}

O ensino superior em saúde, de modo geral, e o ensino médico, em particular, têm sido, nas últimas décadas, alvos de profundas críticas. Em vários países tem crescido o questionamento sobre a capacidade dos cursos de Medicina em cumprirem as finalidades gerais de seus programas, que deveriam ser "desenvolver, no estudante, o potencial intelectual, a capacidade de análise, julgamento e avaliação críti$\mathrm{ca}$, a habilidade para resolver problemas, o raciocínio crítico, a abordagem criativa e inquiridora"1 (p. 43).

Na América Latina, na primeira metade do século 20, predominava na formação médica a influência européia, principalmente da França e da Alemanha². A partir de 1945, com as novas relações econômicas e culturais estabelecidas no mundo, houve diminuição da influência européia, passando a haver influência norte-americana na educação médica, com predominância do modelo flexneriano em reformas sucessivas do ensino superior em saúde, modelo que continua a ter hegemonia na formação em saúde até os dias atuais³.

Há muito tanto as reformas curriculares quanto o projeto pedagógico dos cursos de Medicina têm sido abordados no processo de formação do médico ${ }^{4}$. Verifica-se uma preocupação crescente com a modificação da formação médica, ocasionada pela insatisfação com a realidade existente. Enfatiza-se cada vez mais a necessidade de um profissional apto a atuar e a contribuir com a sociedade em um contexto de profundas mudanças, não somente em seu próprio campo profissional, mas também nos campos político e social ${ }^{4,5}$.

Como reação aos questionamentos sobre a formação, observa-se uma retomada dos estudos e debates sobre a educação médica, com propostas de mudança da formação $0^{4,6-9}$.

A literatura refere-se com insistência à necessidade de formar um médico capaz de conduzir, de forma autônoma, seu processo de aprendizagem ao longo da vida profissional, de adaptar-se e participar das mudanças, com aptidão para raciocinar criticamente, para analisar sistemática e logicamente os problemas e tomar decisões fundamentadas em sua própria avaliação. Os documentos apregoam a necessidade da formação geral e humanística, da responsabilidade do médico perante a sociedade, da valorização da relação médico-paciente e do dever ético da profissão ${ }^{10,11,12}$.

A Comissão Interinstitucional de Avaliação do Ensino Médico (Cinaem) trabalhou durante a década de 1990 com o Projeto Cinaem, desenvolvido em etapas ${ }^{13-16}$. Na segunda fase desse projeto ${ }^{15}$, confirmou-se a "inadequação do processo de formação do médico", tanto em relação ao graduado quanto ao corpo docente e ao modelo pedagógico dos $\operatorname{cursos}^{4}$ (p. 111).
Uma das alternativas usadas para tentar transformar o ensino médico tem sido a incorporação de novas metodologias de ensino ${ }^{17}$. Entre elas ressalta-se a Problem Based Learning $(\mathrm{PBL})^{18}$ ou Aprendizagem Baseada em Problemas, implementada no Brasil em 199719. Além da PBL, outras propostas metodológicas diferenciadas como a Task Based Learning (TBL) ${ }^{20}$ ou Aprendizagem Baseada em Tarefas e a Learning-Oriented-Teaching (LOT) ${ }^{21}$ ou Ensino Orientado para a Aprendizagem, têm sido experimentadas em cursos de Medicina.

O que os fóruns nacionais e internacionais de educação médica têm proposto como alternativa ao paradigma dominante de ensino é o Paradigma da Integralidade $22,23,24$, cujas características são: foco na saúde e não na doença; processo ensino-aprendizagem com ênfase no aluno e em seu papel ativo na própria formação; prática no sistema de saúde em graus de complexidade diferentes; capacitação docente com ênfase tanto na competência técnico-científica quanto na didático-pedagógica; acompanhamento da dinâmica do mercado de trabalho médico orientado pela "reflexão e discussão crítica dos aspectos econômicos e humanísticos da prestação de serviços de saúde e de suas implicações éticas" ${ }^{\prime 4}$ (p. 68).

Na década atual, algumas iniciativas têm tido a responsabilidade de impulsionar mudanças no ensino médico brasileiro, como as Diretrizes Curriculares Nacionais (DCN) ${ }^{10}$, que demonstram preocupação com a consolidação de mudanças nas ações e na formação de recursos humanos em saúde. Outras iniciativas de mudanças estão representadas pelo Programa de Incentivo a Mudanças Curriculares nos Cursos de Medicina (Promed) ${ }^{11}$ e pelo Programa Nacional de Reorientação da Formação Profissional em Saúde (PróSaúde) ${ }^{12}$.

A prática pedagógica é considerada o domínio específico da profissão docente, o que define a identidade profissional do professor, pois reflete a concepção do professor sobre as funções profissionais e o modo como devem ser desempenhadas. Apesar das propostas de transformações nos currículos e no ensino, as mudanças na educação médica têm esbarrado em dificuldades. A prática docente em Medicina tem-se mostrado resistente a modificações, visto que os professores continuam a ensinar como sabem e resistem a novas metodologias de ensino-aprendizagem ${ }^{5.6}$.

Este trabalho procura identificar, por meio de revisão da literatura, os fatores limitantes de mudanças na prática docente em Medicina, com base em autores que discutem a formação de professores no ensino superior e a docência na área médica. 


\section{FATORES LIMITANTES DE MUDANÇAS NA ATUAÇÃO DOCENTE EM MEDICINA}

\section{Desvalorização das Atividades de Ensino e Supremacia da Pesquisa}

Entre os fatores limitantes de mudanças no ensino médico, pode-se citar a insuficiência da abordagem dos problemas educativos próprios da educação médica. Os professores de Medicina tendem a encarar com ceticismo ou descaso os aspectos pedagógicos da docência universitária.

Publicações referentes à docência médica ${ }^{4,18,24-29}$ e à docência universitária ${ }^{30-35}$ são unânimes ao considerarem a existência de uma deficiência no domínio da área educacional, no desempenho do docente do ensino superior. Praticamente não existe, nas escolas médicas, preparo específico para os professores no campo pedagógico. Espera-se que o professor de Medicina seja "um profundo conhecedor do assunto que deve ensinar, como se apenas esse aspecto assegurasse sua competência didática", fato que contribui para a falta de qualificação pedagógica dos docentes ${ }^{25}$ (p. 34).

A pouca valorização dada à formação pedagógica do professor universitário pode ser atribuída ao desmerecimento das atividades de ensino nas universidades, nas quais os estímulos para a atuação e os critérios de progressão na carreira têm-se fundamentado mais na produção científica que no exercício da docência. Contribui para esse fato o próprio desenvolvimento do conhecimento científico específico de cada área, que tem se tornado cada vez mais fragmentado e incapaz de explicar a complexidade dos fenômenos educativos.

Para os professores de Medicina, a docência é considerada uma atividade secundária à profissão médica, e o trabalho docente "não se configura como uma profissão"25 (p. 32). Um fator que contribui para essa constatação é que o critério de contratação dos docentes nos cursos médicos é centrado, principalmente, na qualidade de seu desempenho em sua área técnica de atuação.

Além disso, os professores de Medicina, freqüentemente, são contratados pelo trabalho desenvolvido em pesquisa e publicações científicas e não pela capacidade de ensinar, conforme observam Finucane e Rolfe ${ }^{27}$, McLeod et al. ${ }^{28}$ e McLe$\mathrm{an}^{29}$, fator que os leva a se afastarem das atividades docentes. Pesquisar e ensinar "não são atividades incompatíveis, mas competem no tempo disponível do docente/pesquisador"4 (p. 154-155).

Apesar de as instituições de ensino serem basicamente formativas e, dessa forma, a formação oferecida aos estudantes deveria constituir a variável de maior importância, o ranking é feito com base em indicadores de produção científica ou técnica e, assim, o potencial formativo fica secundarizado. Muitas vezes, "os professores vêem a si mesmos mais como pesquisadores (no campo científico) ou como profissionais (no campo aplicado) do que como professor de fato"34 (p. 114).

Entidades que incentivam/promovem a educação médica, como a Organização Mundial da Saúde (OMS), recomendam que o desenvolvimento docente se torne integrado ao processo de reforma curricular. Consideram também que, nas escolas médicas, as atividades de ensino deveriam ter o mesmo valor dado às atividades de pesquisa, e os indicadores de competência em ensino deveriam ser estabelecidos e conside$\operatorname{rados}^{29}$.

Com esta realidade, atrair e reter professores qualificados na área médica continua um desafio, pois apenas recentemente os professores universitários vêm se tornando conscientes de que a atividade docente, como a pesquisa e a prática de qualquer profissão, exige capacitação própria e específica. A desvalorização das atividades relacionadas à formação docente, portanto, prejudica a qualidade do ensino ministra-

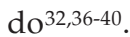

\section{Falta de Profissionalização Docente}

A docência universitária "exige não apenas domínio de conhecimentos a serem transmitidos por um professor como também um profissionalismo exigido para o exercício de qualquer profissão"38 (p. 30).

A profissionalidade da docência reside nas exigências intelectuais e habilidades práticas que seu exercício implica. Os professores são reconhecidos como profissionais justamente pelo domínio técnico demonstrado na solução de problemas, ou seja, devem conhecer os procedimentos adequados de ensino e sua aplicação ${ }^{41}$. Afinal, os professores são profissionais não apenas porque sabem ou recebem um salário, mas principalmente porque o trabalho que executam exige vários conhecimentos e competências, e é de grande relevância soci$\mathrm{al}^{34}$.

Muito esforço tem sido feito para formar bons médicos, mas pouca atenção tem sido dada ao conceito de desenvolvimento profissional do médico que atua como professor. Isso pode ser atribuído ao fato de a falta de aplicação técnica de grande parte do conhecimento pedagógico, juntamente com a natureza ambígua e, por vezes, conflituosa de seus fins, ter levado a se considerar o ensino como uma profissão "somente em um sentido muito fraco e limitado"41 (p. 95).

A identidade dos docentes de Medicina freqüentemente evolui com o tempo e a experiência. O modo como os profissionais se tornam aptos a desempenhar seu papel é um pro- 
cesso que ocorre ao longo da vida, se inicia na graduação $\mathrm{O}^{41,42,43}$ e tem estimulado investigações como a realizada por Stone et al. ${ }^{44}$ para identificar como os professores da área clínica do curso de Medicina, considerados excelentes por seus pares, estabelecem sua identidade profissional como médico e como docente.

Historicamente, a docência tem sido assumida como profissão genérica e não como ofício, por ser considerada socialmente uma "semiprofissão", com alguns traços característicos, como o predomínio do conhecimento objetivo, ou seja, o conteúdo específico de disciplinas: "Saber, ou seja, possuir um certo conhecimento formal, era assumir a capacidade de ensiná-lo"45 (p. 13.) No momento, essas características históricas são consideradas insuficientes, embora não se discuta que sejam necessárias ${ }^{18}$.

Atuar como professor significa desenvolver funções de natureza distinta. Envolve desde as funções de rotina, que podem ser aprendidas por treinamento, até funções mais complexas, de tomada de decisão, que resultam, principalmente, de características pessoais do professor e têm caráter imprevisível, por ocorrerem de acordo com as exigências do momento, e refletem a dimensão interior e a teoria implícita na atuação dos professores ${ }^{41}$.

A identidade profissional dos professores de Medicina (o que sentem sobre o que são, sobre o que sabem; os livros que lêem ou escrevem, os colegas com quem se relacionam, os congressos que freqüentam, as conversas profissionais que mantêm, etc.) costuma estar mais centrada em suas especialidades científicas do que em sua atividade docente.

Para Nóvoa46, o termo mais adequado seria "processo identitário", por realçar a mistura dinâmica que caracteriza a maneira como cada um se sente e se diz professor, pois a “identidade não é um dado adquirido, não é uma propriedade, não é um produto. [...] é um espaço de construção de maneiras de ser e de estar na profissão". O autor denomina "segunda pele profissional" as características próprias que os docentes adquirem a partir da experiência: o modo próprio de organizar as aulas, de movimentar-se na sala, de dirigir-se aos alunos, de utilizar os recursos pedagógicos.

Segundo Zabalza ${ }^{34}$, existem três dimensões na definição do papel do docente de ensino superior: 1) dimensão profissional: elementos que definem a profissão, como a construção da identidade, os dilemas do exercício profissional e as necessidades de formação inicial e permanente; 2) dimensão pessoal: tipo de envolvimento e de compromisso pessoal, ciclos de vida dos docentes, situações e problemas pessoais que acompanham o exercício profissional, fontes de satisfação e insatisfação no trabalho; 3) dimensão administrativa: condições con- tratuais, sistemas de seleção e promoção, incentivos e obrigações vinculadas à atuação profissional.

Petra et al. ${ }^{47}$, em contrapartida, consideram os três domínios de conhecimentos docentes: o ideológico, que determina as normas, os valores e os objetivos existentes em educação; o empírico, que conecta os fenômenos da realidade educacional; e o domínio tecnológico: dos métodos, técnicas e estratégias educacionais.

Stone et al. ${ }^{44}$ ressaltam que, para o indivíduo sentir-se como profissional, devem ocorrer mudanças tanto externas como internas, subjetivas. Externamente, aprendem-se novas informações e desenvolve-se um novo grupo social, enquanto se adquirem os conhecimentos específicos da profissão. Na transformação profissional interna, a profissão passa a ser vista como um chamado ou como uma conceituação subjetiva associada ao papel desempenhado. O terceiro e último fator a ser considerado na profissionalização é o mentoring, ou seja, o fato de profissionais experientes darem assistência aos iniciantes. Todos esses elementos estão presentes na formação da identidade dos médicos que, recém-formados, aprendem informações novas, integram-se em um novo grupo de especialistas, são monitorados como residentes, o que geralmente não ocorre com os médicos que optam pela docência.

Conforme afirmam Batista e Ribeiro ${ }^{48}$, enfrentar a questão da profissionalização do professor de Medicina é um trabalho árduo, visto que demanda esforço para localizar as diferentes situações que perpassam a categoria docente, mapear os conflitos e as contradições que permeiam a prática dos professores, além de "compreender a complexidade que envolve as funções de ensino, de educação e saúde nesta sociedade" (p. 7).

Para McLean ${ }^{29}$, embora se acredite na existência de critérios que determinem a eficácia e a eficiência em docência, eles são vagos e de difícil implementação. Apesar de estudos 48 apresentarem propostas de atividades para os cursos de Medicina incentivarem o desenvolvimento da identidade do médico como professor, a identidade profissional docente não pode ser pensada separada da perspectiva da formação docente, em vista da interdependência de ambos os fatores. Afinal, a atividade docente nas universidades necessita ser encarada de forma profissional e não amadorística, pois, além das competências específicas para o exercício de uma profissão, existem as competências próprias do docente universitário, seja em determinada área do conhecimento, seja no domínio da área pedagógica, seja no imprescindível exercício da dimensão política da docência universitária, em outras palavras, na visão de educação, de homem e de mundo do professor. 


\section{Desvalorização da Formação Docente do Professor de Medicina}

O corpo docente é o alicerce fundamental sobre o qual devem ser instituídas as bases das mudanças introduzidas na educação médica, e a docência universitária tem constituído tema relevante de pesquisa na área educacional e na área de educação médica ${ }^{18,30,32,36-40,49-53}$.

No Brasil, na terceira fase do Projeto Cinaem ${ }^{16}$, que se centrou no processo de formação e na docência médica, houve consenso acerca do "despreparo da maioria dos docentes que, na quase totalidade, são especialistas, não havendo modelo de identificação para o propósito da formação geral do médico" ${ }^{\prime \prime}$. Afirmou-se a importância do corpo docente das escolas médicas como "um dos elementos centrais do êxito das reformulações necessárias à educação médica" e recomendou-se que os cursos médicos promovessem "a excelência dos médicos para a docência", e, dessa forma, contribuíssem para a transformação da formação $0^{16}$ (p. 11).

De modo geral, a formação do professor começa antes mesmo de sua formação acadêmica e prossegue durante toda a vida profissional, estando baseada em processos complexos principalmente porque a prática educativa se constitui na tensão entre as determinações estruturais da sociedade e as exigências do sistema de ensino ${ }^{54}$.

A atuação do docente da área médica restringe-se, geralmente, à reprodução dos modelos considerados válidos, aprendidos anteriormente, e à sua experiência prática cotidiana ${ }^{26,27}$. Os professores têm idéias, atitudes e comportamentos sobre o ensino provenientes da formação recebida durante o período em que foram alunos. Nessa formação existe uma dimensão inconsciente e não inteiramente racional que se enquadra no que Mizukami ${ }^{55}$ denomina "teoria prática de ensino", pois os professores "operam na base de várias teorias da prática e, quer estejam ou não conscientes de tais teorias, seu trabalho é racional, pelo fato de ser intencional" (p. 43).

A influência que essa formação incidental exerce é considerável, posto que os docentes a adquirem de forma nãoreflexiva, como algo natural, escapando, assim, a críticas e transformando-se em um conceito espontâneo sobre o que seja ensinarr6,57. Entre os limites dessa formação, Venturelli18 cita a improvisação como "la mejor forma de eternizar las limitaciones de un método que el tiempo ha sobrepasado", pois limita a discussão e a reflexão sobre as práticas executadas e, com isso, a possibilidade de enriquecimento teórico com leituras e ampliação da visão de mundo do docente. Benedito ${ }^{58}$ acrescenta que, embora não se deva desconsiderar a capacidade autodidata do professorado, a formação proporcionada pela experiência é insuficiente (p. 23).
Na verdade, aprende-se a ser professor universitário "mediante um processo de socialização em parte intuitiva, autodidata ou [...] seguindo a rotina dos outros" ${ }^{\prime \prime 58}$ (p. 131). Nesse processo, têm papel mais ou menos importante a experiência própria como aluno, o modelo de ensino predominante no sistema universitário e as reações dos estudantes. O professor passa da experiência passiva como aluno ao comportamento ativo como professor "sem que lhe seja colocado, em muitos casos, o significado educativo, social e epistemológico do conhecimento que transmite ou faz seus alunos aprenderem" ${ }^{\prime \prime 59}$ (p. 153).

Para Venturelli18, se as instituições de ensino médico reconhecessem o fato de que o médico sabe Medicina, mas não foi formado para ensinar, poderiam contribuir para mudar a situação, direcionando os professores atuais e futuros a um caminho "de aprendizaje, de real formación docente", o que permitiria "poner la educación del futuro profesional de la salud en una dirección altamente propicia" (p. 23).

Existem diferentes concepções de formação docente em saúde: a da formação como processo de reflexão e a da formação como treinamento didático/exercício docente ${ }^{60}$. Esse tema é considerado complexo por "expressar tensões entre perspectivas teórico-metodológicas que buscam contribuir para a formulação de políticas de formação que extrapolem as meras situaç̃oes de capacitação e atualização"60 (p. 17). De qualquer modo, a formação docente permanente é imprescindível para favorecer a evolução da formação médica, fato reconhecido atualmente não só pelos cursos que usam novas estratégias de ensino, mas até mesmo pelos tradicionais ${ }^{61}$.

Apesar dos vários paradigmas sobre a formação inicial dos docentes, existe um "escasso desenvolvimento teórico e conceptual da formação permanente ou desenvolvimento profissional dos docentes" (p. 32) (2. Giroux $^{63}$ aponta como uma das maiores ameaças para a atuação dos professores o desenvolvimento de ideologias instrumentais de formação com ênfase na abordagem tecnocrática para a preparação docente e para as práticas em sala de aula, que prejudicam tanto a natureza do ensino quanto os alunos que, "em vez de aprenderem a refletir sobre os princípios que estruturam a vida e a prática em sala de aula, [...] aprendem metodologias que parecem negar a própria necessidade de pensamento crítico" (p. 159). O autor propõe, como forma de reestruturar a atividade docente, considerar os professores como "intelectuais transformadores", educadores e críticos das teorias tecnocráticas e instrumentais da educação, podendo propiciar o repensar das tradições e das condições que os têm impedido de assumir um papel ativo e reflexivo. 
Gimeno Sacristan ${ }^{59}$ considera que o processo de renovação pedagógica que preconiza o papel central para os professores no planejamento de sua prática deve partir da análise das condições objetivas do trabalho profissional dos docentes, "para propiciar saídas realmente libertadoras, ao mesmo tempo que se é consciente das dificuldades objetivas do plano" (p. 109).

A crítica generalizada ao tradicionalismo e à racionalidade técnica tem conduzido à emergência de propostas alternativas sobre o papel do professor, com a visão da formação em uma perspectiva mais ampla e mais humana. Na verdade, as teorias tradicionais de formação de professores foram colocadas em discussão porque os cursos de formação, ao desenvolverem um currículo formal, têm contribuído de forma insatisfatória para a geração de uma nova identidade profissional docente.

Estudiosos de vários países têm manifestado preocupação com a necessária mudança no trabalho docente. $\mathrm{O}$ ensino tradicional vem paulatinamente dando lugar a práticas alternativas que se propõem levar ao desenvolvimento global dos educandos ${ }^{49,64}$.

O conceito mais utilizado por investigadores, formadores de professores e educadores diversos para se referirem às novas tendências da formação de professores é o da "prática reflexiva"65,66, proposta por Schön 66,67 e que causou grande interesse e influência nos trabalhos direcionados à prática profissional docente. Schön ${ }^{67}$ sugere a incrementação das práticas reflexivas e o estímulo a sua introdução na formação docente, para que os professores possam aprender a partir da análise e da interpretação de sua própria atividade. O professor reflexivo, que pensa-na-ação, se interroga sobre as alternativas possíveis para determinado momento e avalia seus resultados.

Entre os obstáculos à implantação da prática reflexiva encontram-se a epistemologia dominante na universidade e o currículo prescritivo. Nóvoa ${ }^{46}$, ao defender a formação docente como um processo interativo e dinâmico, apregoa a necessidade de estímulo a uma perspectiva crítico-reflexiva, que forneça ao professor meios de desenvolver um pensamento autônomo e de compreender a globalidade do sujeito.

Para verificar a eficácia e eficiência de cursos de capacitação docente, Godfrey et al. ${ }^{68}$ pesquisaram as mudanças ocorridas nas atividades de ensino de dois grupos de professores de Medicina: um constituído pelos que participaram de um curso de docência; e o outro integrado por docentes em lista de espera pelo curso, considerado Grupo Controle. Após um período de 8-10 meses, os professores responderam ao mesmo questionário aplicado antes do curso, e a maioria dos participantes relatou mudanças positivas na prática pedagógica, maiores que as do Grupo Controle.
O caminho aberto pela necessidade da reflexão como modelo de formação docente propõe uma série de intervenções que torna possível, em nível teórico e prático, um novo modo de formar professores. Apesar das críticas feitas à proposta de Schön, é inegável sua contribuição para uma nova visão da formação. O ponto principal da crítica a Schon é que o conhecimento pode e vem da prática, mas não há como situá-lo exclusivamente nela. Esta crítica, na verdade, deve ser dirigida à racionalidade técnica, que defende a idéia de que os profissionais solucionem problemas através de meios técnicos. O questionamento a este tipo de profissionalização é que, quando se esgotam o repertório teórico e os instrumentos construídos como referenciais, o profissional não sabe como lidar com a situação.

\section{Resistência Docente a Mudanças}

Outro fator que limita mudanças no ensino médico é a resistência dos professores a transformações. Um dos aspectos que podem contribuir para essa resistência é que as tentativas de mudança ocasionam certa sensação de insegurança, o chamado "mal-estar docente", visto que os professores já se encontram adaptados "a um trabalho bem definido - o ensino, a transmissão de conhecimentos"69 (p. 11).

Existem vertentes diferenciadas de prática pedagógica ${ }^{64,70}$. Schmidt et al. .4 $^{6}$ consideram a prática pedagógica "repetitiva", em que as ações docentes parecem acontecer "sem dúvidas e reflexões", e a prática pedagógica "reflexiva", que se preocupa com mudanças qualitativas no processo de ensino e procura instrumentalizar-se com um conhecimento crítico e aprofundado da realidade (p. 23). Cunha ${ }^{30}$ emprega outra nomenclatura para as práticas/concepções de ensino: uma "reprodutiva", na qual "prepondera a reprodução do conhecimento cientificamente acumulado", e outra, "emergente", que concebe o conhecimento como um processo "onde a dúvida e a incerteza são estímulos à produção do aprendiz" (p. 389).

Estarão os professores da área da saúde aptos a classificar sua própria prática docente? Estarão preparados para a implementação da prática reflexiva ou necessitam de orientação, estímulo e cooperação?

Ten Cate et al. ${ }^{21}$ consideram que os professores de Medicina apresentam dificuldades de compreender as concepções curriculares subjacentes aos currículos e de colocá-las em prática. O autor apregoa a necessidade de que as propostas sejam bem claras para auxiliar os docentes a refletir sobre a prática cotidiana, analisar as atitudes/reações dos alunos, desenvolver e implementar novos métodos de ensino e compreender por que determinadas estratégias não conseguem estimular a aprendizagem. 
Apesar das dificuldades que os professores de Medicina apresentam em relação às questões educativas, Swick ${ }^{71}$ considera que, se por um lado, as mudanças trazem inevitavelmente desafios e sentimentos de perda, por outro, também oferecem a oportunidade de reconstruir o ensino médico em direção às necessidades da sociedade.

Clack $^{72}$ concorda em que a resistência docente é um fator limitante de mudanças no ensino médico e relata o papel positivo da avaliação realizada em um curso de Medicina do Reino Unido que, ao mudar seu currículo, realizou uma investigação com egressos sobre o ensino ministrado. Foram devolvidos 78\% dos questionários e apontadas as deficiências em vários aspectos da formação, com um efeito imediato de implementar algumas alterações práticas no currículo para corrigir as deficiências apontadas.

Aliás, a avaliação tem sido um instrumento usado para efetivar mudanças em cursos de Medicina e Odontologia ${ }^{73,74} \mathrm{e}$ é considerada válida para avaliação curricular. Não basta, entretanto, apenas aplicar instrumentos de avaliação. Para Wolfhagen $^{75}$, o sucesso dos processos avaliativos encontra-se no desejo de adotar uma atitude crítica, de analisar a situação existente, na oportunidade de discutir e dialogar, na disponibilidade de executar um plano de ação e de coletar dados continuamente.

\section{Individualismo da Ação Docente}

O individualismo presente na docência universitária é apontado por Bireau ${ }^{31}$ como um dos obstáculos à formação docente. A autora assinala que os docentes do ensino superior são dominados pela "síndrome de ensinar à minha maneira", um dos fatores que os leva a adotar estilos pedagógicos que têm tanto de pessoal como de empírico. E acrescenta que cada docente "é rei e senhor do conteúdo a ministrar". Para Zabalza $^{34}$, os professores universitários agem como se cada um fosse uma espécie de "célula fechada e autônoma".

$\mathrm{O}$ individualismo não é exclusividade dos professores de Medicina, tendo sido reconhecido em outros países como uma característica da docência universitária ${ }^{34,47,76}$. Estudo realizado concomitantemente em universidades francesas e alemãs evidencia a falta de integração e o individualismo em que se processa a docência. A distribuição das disciplinas entre os professores leva em conta as pretensões e as preferências de cada docente, e não se aprofunda a discussão dos conteúdos e/ou métodos pedagógicos ${ }^{31}$.

Para Petra et al. ${ }^{47}$, quando os professores agem de forma individual, independente, tendem a desenvolver principalmente o domínio técnico da função docente, pois os demais, o ideológico e o empírico, geralmente são proporcionados pela reflexão sobre o trabalho realizado. $\mathrm{O}$ autor pondera que, se os gestores do ensino dessem mais atenção a todos os domínios do conhecimento docente, mais professores poderiam se desenvolver.

Investigação realizada sobre as práticas educativas de professores de Medicina de uma instituição federal de ensino superior $^{76}$ observou o individualismo e o predomínio da racionalidade técnica na ação do professor. Quando a racionalidade técnica é norteadora da prática, fica subentendido que o que se requer dos professores é que executem atividades preestabelecidas para a consecução de determinados objetivos. Para isto, o docente aplica métodos e adere a rotinas cristalizadas: não faz parte do seu exercício profissional o questionamento do ensino, mas tão-somente seu cumprimento eficaz.

A racionalidade técnica implanta a figura do expert, que, com sua eficiência e domínio das técnicas derivadas do conhecimento científico, legitima os "objetivos que ficam fora do debate tanto para os professores como para a sociedade" 41 .

$\mathrm{O}$ individualismo presente na prática docente universitária é um dos entraves ao desenvolvimento dos professores desse nível de ensino, pois vivem "tão intensamente a autonomia ideológica, científica, didática, que se torna inexpressivo qualquer processo que tenda a romper esse status quo" 34 (p. 118).

Segundo Costa ${ }^{76}$, "o currículo estruturado em disciplinas é o meio ideal para cultivar o professor que trabalha isoladamente, pois cada disciplina existe de forma independente e sem comunicação com as demais" (p. 123). Em outras palavras, a forma de organização dos currículos tende a legitimar o isolamento da ação docente e deve ser considerada quando se pensa em transformar a formação de profissionais de saúde.

\section{CONSIDERAÇÕES FINAIS}

São vários os desafios a serem enfrentados pelos estudiosos da educação médica, principalmente se há objetivos de mudanças na prática docente. Um dos itens considerados básicos é a formação dos professores, visto que precisam de uma visão global da profissão docente e não apenas de sua especialidade médica.

Com a ressignificação do papel docente, de transmissor de conhecimentos para mediador e facilitador da aprendizagem dos alunos, é importante ter clareza teórica sobre pontos como: o que significa ser um bom professor? O que é entendido por excelência em docência?

Assim, encontrar estratégias práticas adequadas ao fazer docente constitui uma tarefa essencial para a formação do educador. Afinal, a docência médica deve ser vista em um 
continuum que só cessa ao final da vida profissional, e seria desejável que todos os professores - sejam os que se dedicam à pesquisa, sejam os que se preocupam com o ensino - juntassem forças para o desenvolvimento permanente da docência médica.

As iniciativas vêm, em geral, de indivíduos isolados ou de pequenas equipes, e só em casos muito raros a instituição se interessa por elas. Afinal, se mudanças efetivas no papel do professor de Medicina são desejadas, deve-se pensar com a clareza que oportunize a geração de propostas concretas, que passam obrigatoriamente pela incorporação institucional do desenvolvimento pedagógico permanente dos docentes da área da saúde.

\section{REFERÊNCIAS}

1. Mamede S, Penaforte J, org. Aprendizagem baseada em problemas: anatomia de uma nova abordagem educacional. Fortaleza: Hucitec; 2001.

2. Chaves M, Kisil M. Origens, concepção e desenvolvimento. In: Almeida MJ, Feuerwerker L, Llanos, CM, org. A educação dos profissionais de saúde na América Latina: teoria e prática de um movimento de mudança. [Tomo I]. São Paulo: Hucitec; 1999. p. 1-16.

3. Almeida MJ. A educação dos profissionais de saúde na América Latina: teoria e prática de um movimento de mudança. São Paulo: Hucitec;1999.

4. Lampert JB. Tendências de mudança na formação médica no Brasil: tipologia das escolas. São Paulo: Hucitec/ABEM; 2002.

5. Koifman L. A teoria de currículo e a discussão do ensino médico. Rev. Bras. Educ. Med. 1998; 22: 37-47.

6. Feuerwerker L. Além do discurso de mudança na educação médica: processos e resultados. São Paulo: Hucitec; Londrina: Rede Unida; Rio de Janeiro: ABEM; 2002.

7. Asua M. Evolution de la formación medica en las facultades de medicina, Argentina, 1900-1982. Educ Med y Salud. 1986; 20: 265-271.

8. Laguna JA. La modernizacion del cientificismo y el arcaísmo nacional actual: el caso de la formación medica en el Peru. Educ Med y Salud. 1992; 26: 54-69.

9. Almeida MJ. A educação médica e as atuais propostas de mudança: alguns antecedentes históricos. Rev. Bras. Educ. Med. 2001; 25: 42-52.

10. Ministério da Educação. Conselho Nacional de Educação. Resolução CNE/CES no 4, de 01/11/2001. Diretrizes Curriculares Nacionais do Curso de Graduação em Medicina. Brasília: Câmara de Educação Superior; 2001.
11. Ministério da Saúde/ Ministério da Educação/ Organização Panamericana da Saúde. PROMED - Programa de Incentivo a Mudanças Curriculares nos Cursos de Medicina. Brasília: Secretaria de Políticas da Saúde; 2002. [Edital de Convocação]

12. Ministério da Saúde. Ministério da Educação. Programa nacional de reorientação da formação profissional em saúde PRÓ-SAÚDE. Brasília - DF, 2005, 80p. Disponível em: <http: / / portal.saude.gov.br/portal/sgtes / visualizar_texto.cfm?idtxt=22848>, [Acesso em: 02 de março de 2006].

13. Associação Brasileira de Ensino Médico. III Fórum nacional de avaliação do ensino médico. Anais do XXXII Congresso Brasileiro de Educação Médica. Niterói: ABEM;1994.

14. Associação Brasileira de Ensino Médico. IV Fórum nacional de avaliação do ensino médico. Anais do XXXIII Congresso Brasileiro de Educação Médica. Porto Alegre: ABEM;1995.

15. Comissão Interinstitucional de Avaliação do Ensino Médico. Relatório final da II fase do projeto de avaliação da educação médica no Brasil. Rio de Janeiro: CINAEM;1997.

Comissão Interinstitucional de Avaliação do Ensino Médico. Projeto Cinaem/ III Fase. Processo de formação e docência. Rio de Janeiro: CINAEM;1999.

16. Angeli AO, Loureiro SR. A aprendizagem baseada em problemas e os recursos adaptativos de estudantes do curso médico. Rev. Bras. Educ. Med 2001; 25: 32-41.

17. Venturelli, J. Educación médica: nuevos enfoques, metas y métodos. Washington: OPS; 1997.

18. Komatsu RS, Zanolli MB, Lima VV. Aprendizagem baseada em problemas: In: Marcondes E, Lima-Gonçalves E, org. Educação médica. São Paulo: Sarvier; 1998. p.223-237.

19. Harden RM, Laidlaw JM, Ker JS, Mitchell, HE. Task-based learning: an educational strategy for undergraduate, postgraduate and continuing medical education. Med. Teach. 1996; 18: 7-13.

20. Ten Cate O, Snell L, Mann K, Vermunt J. Orienting teaching toward the learning process. Acad. Med. 2004; 79: 219-228.

21. Feuerwerker L. Educação médica na América Latina. In: Feuerwerker, L. Mudanças na educação médica e residência médica no Brasil. São Paulo: Hucitec/Rede Unida; 1998, p. 51-95.

22. Campos FE, Ferreira JR, Feuerwerker L, Sena RR, Campos JJB, Cordeiro H, Cordoni Jr L. Caminhos para a aproximar a formação de profissionais de saúde das necessidades da atenção básica de saúde. Rev. Bras. Educ. Med. 2001; 25: 11-26. 
23. Lampert JB. Na transição paradigmática: o que o paradigma da integralidade atende que o paradigma flexneriano deixou de lado. Cadernos ABEM. 2004; 1: 23-25.

24. Batista NA, Souza Silva SH. A função docente em medicina e a formação/educação permanente do professor. Rev. Bras. Educ. Med. 1998a; 22: 31-36.

25. Batista NA, Souza da Silva SH. O professor de medicina: conhecimento, experiência e formação. São Paulo: Loyola; 1998b.

26. Finucane P, Rolfe I. Graduates' verdict on medical teachers: the minority who teach do it well. Med Teach. 1996; 18: 57- 59.

27. McLeod PJ, Steinert Y, Meagher T, Mcleod A. The ABCs of pedagogy for clinical teachers. Med Educ. 2003; 37: 638644.

28. McLean, M. Reawarding teaching excellence. Can we measure teaching "excellence"? Who should be the judge? Med Teacher. 2001; 23(1): 6-11.

29. Cunha MI. O futuro já é hoje: o desafio políticoepistemológico do ensino superior na sociedade contemporânea. Anais do VII Encontro Nacional de Didática e Prática de Ensino; 1994, Goiânia: ENDPE;1994. p.382-394.

30. Bireau A. Os métodos pedagógicos no ensino superior. Porto, Portugal: Porto Ed.; 1995.

31. Abreu MC, Masetto MT. O professor universitário em aula. São Paulo: MG Ed; 1997.

33. Pimenta SG; Anastasiou LG. Docência no ensino superior. São Paulo: Cortez; 2002.

34. Zabalza MA. O ensino universitário: seu cenário e protagonistas. São Paulo: Artmed; 2004.

35. Perez Gómez AP. O pensamento prático do professor: a formação do professor como profissional reflexivo. In: Nóvoa, A, org. Os professores e sua formação. Lisboa: Dom Quixote; 1997. p. 95-114.

36. Cunha MI. O professor universitário na transição de paradigmas. Araraquara: JM; 1998.

37. Masetto MT, org. Docência na universidade. Campinas: Papirus; 1998.

38. Masetto MT. O professor universitário e sua formação pedagógica. In: Bicudo MAV, Silva Junior CA. Formação do educador e avaliação educacional: formação inicial e contínua. São Paulo: Unesp; 1999.

39. Masetto MT. Competência pedagógica do professor universitário. São Paulo: Summus; 2003.

40. Castanho MELM. A criatividade na sala de aula universitária. In: Veiga, IPA, Castanho MELM. Pedagogia universitária: a aula em foco. Campinas: Papirus; 2000. p.75-89.
41. Contreras J. A autonomia de professores. São Paulo: Cortez; 2002.

42. Paquay L, Perrenoud P, Altet M, Charlier E. Formando professores profissionais. Porto Alegre: Artmed; 2001.

43. Perrenoud P, Thurler MA. As competências para ensinar no século XXI. Porto Alegre: Artmed; 2002.

44. Stone S, Ellers B, Holmes D, Orgren R, Qualters D, Thompson J. Identifying oneself as a teacher: the perceptions of preceptors. Med Teach, 2002; 36: 180-185.

45. Imbernón F. Formação docente e profissional: formar-se para a mudança e a incerteza. São Paulo: Cortez; 2001.

46. Nóvoa A. Formação de professores e profissão docente. In: Nóvoa, A, org. Os professores e sua formação. Lisboa: Publicações Dom Quixote; 1997. p.15-33.

47. Petra PAXJ; Beijaard D, Wubbels T. Teachers' development of professional knowledge through action research and the facilitation of this by teacher educators. Teaching and Teacher Education 2004;6: 571-588.

48. Batista N, Ribeiro ECO. Projeto Cinaem. Docência médica profissionalizada. Relatório de Consultoria. Rio de Janeiro: Cinaem; 1999.13p. (mimeo)

49. Morosini MC, org. Professor do ensino superior: identidade, docência e formação. Brasília: Plano; 2001.

50. Batista N, Batista SH. A formação do professor universitário em saúde: desafios e possibilidades. In: Severino AJ, Fazenda IC. Formação docente: rupturas e possibilidades. Campinas: Papirus;2002. p.185-205.

51. Batista N, Batista SH, orgs. Docência em saúde: temas e experiências. São Paulo: Senac; 2004 a. p.17- 31.

52. Behrens MA, org. Docência universitária na sociedade do conhecimento. Curitiba: Champagnat; 2003.

53. Pimenta SG, Anastasiou LC, Cavallet, VJ. Docência e ensino superior: construindo caminhos. In: Barbosa, RL, org. Formação de educadores: desafios e perspectives. São Paulo: Unesp; 2003. p.267-278.

54. Santos LLCP. Formação do professor e pedagogia crítica. In: Fazenda I, org. A pesquisa em educação e as transformações do conhecimento. Campinas: Papirus; 1997. p. 1727.

55. Mizukami MGN. Teoria, prática e reflexão na formação do profissional em educação. [Goiânia] Inter-ação 1997; 21: 39-60.

56. Perrenoud P. Práticas pedagógicas: profissão docente e formação: perspectivas sociológicas. Lisboa: Dom Quixote; 1993. 
57. Carvalho, AMP. Paradigmas e métodos de investigação nas práticas de ensino: aspectos epistemológicos. Anais do VII Encontro Nacional de Didática e Prática de Ensino; 1994. Goiânia: ENDPE; 1994. p.79-90.

58. Benedito A V. La formación universitaria a debate. Barcelona: Universidad de Barcelona; 1995.

59. Gimeno Sacristán J. O Currículo: uma reflexão sobre a prática. Porto Alegre: Artmed; 2000.

60. Batista N, Souza da Silva SH. A docência em saúde: desafios e perspectivas. In: Batista N, Batista SH, orgs. Docência em saúde: temas e experiências. São Paulo: Senac; 2004.

61. Venturelli J, Fiorini V. Programas educacionais inovadores em escolas médicas: capacitação docente. Rev. Bras. Educ. Med, 2001; 25: 7- 21.

62. Garcia CM. Formação de professores: para uma mudança educativa. Porto: Porto Editora; 1995. 272p.

63. Giroux HA. Os professores como intelectuais: rumo a uma pedagogia crítica da aprendizagem. Porto Alegre: Artes Médicas, 1997.

64. Schmidt LM, Ribas MH, Carvalho MA. A prática pedagógica como fonte de conhecimento. In: Alonso M, org. O trabalho docente: teoria e prática. São Paulo: Pioneira;1999. p. 20-36.

65. Garcia CM. A formação de professores: novas perspectivas baseadas na investigação sobre o pensamento do professor. In: Nóvoa, A, org. Os professores e sua formação. Lisboa: Dom Quixote; 1997.p. 51-73.

66. Schon D. Educando o profissional reflexivo. Porto Alegre: Artmed; 2000a.

67. Schon D. Formar professores como profissionais reflexivos. In: Nóvoa, A, org. Os professores e sua formação. Lisboa: Publicações Dom Quixote; 1997b. p.77-91.

68. Godfrey J; Dennick R; Welsh C. Training the trainers: do teaching courses develop teaching skills? Medical Education $2004 ; 38: 844-847$
69. Alonso M. org. O trabalho docente: teoria e prática. São Paulo: Pioneira; 1999. p. 20-36.

70. Perez Gómez A. A função e a formação do professor/a no ensino para a compreensão: diferentes perspectivas. In: Gimeno Sacristán J, Perez Gómez A. Compreender e transformar o ensino. Porto Alegre: Artes Médicas; 1998. p.353379.

71. Swick HM. Academic medicine must deal with the clash of business and professional values. Academic Medicine 1998; 73(7): 751-755.

72. Clack GB. Evaluation by graduates: a tool to stimulate change? Medical Teacher 1997;19(1): 32-35.

73. Friedeberg M; Shimon MG. Evaluation of innovative school's graduates by department heads at other hospitals. Medical Teacher 1997; 19(1):36-39.

74. Fry H; Jones A; Davenport E; Brook A. Changing curricula: an evaluation from dentistry. Medical Teacher 1997;19(2):108-113.

75. Wolfhagen H; Gijselaers WH; Dolmans, D; Essed G; Schmidt H.G. Improving clinical education through evaluation. Medical Teacher 1997; 19(2):99-103.

76. Costa NMSC. A formação e as práticas educativas de professores de medicina: uma abordagem etnográfica. [tese] São Paulo: Pontifica Universidade Católica de São Paulo; 2005. 201p.

\section{Conflito de Interesse}

Declarou não haver.

\section{Endereço para Correspondência}

Nilce Maria da Silva Campos Costa Rua 15 n 220/100 Setor Oeste 74140-035 Goiânia-Goiás 